\title{
ASSESSMENT OF SELECTED DETERMINANTS OF BURNOUT SYNDROME AND COPING STRATEGIES IN TERMS OF GENDER IN ENTREPRENEURS

\author{
Barbara Nicole Čigarská ${ }^{1}$, Zuzana Birknerová ${ }^{2}$
}

\begin{abstract}
Nowadays, the issue of burnout syndrome is relatively extensive and increasingly manifested. Although burnout syndrome can affect anyone, certain differences in its occurrence are noticeable, especially in personality traits, gender, or the character of work. This article aims to assess the signals of burnout syndrome and coping strategies in terms of gender. The main determinants of burnout syndrome are Emotional Exhaustion, Depersonalization, and Personal Accomplishment and are included in the Maslach Burnout Inventory, consisting of twenty-two questions, separately dealing with mentioned individual determinants. The Brief Cope inventory, which outlines fourteen strategies about how to cope with stress, was used to find out which coping strategies entrepreneurs used in difficult situations. The research was carried on a representative sample of entrepreneurs $(\mathrm{N}=113)$ in the Slovak Republic by online questionary. The result of the analysis reported the existence of statistically significant differences $(\mathrm{p}<.05)$ between determinants of burnout syndrome and coping strategies in terms of gender among entrepreneurs in the assessment of selected determinants. Entrepreneurs used mostly problem-focused coping strategies like Active coping and Planning, an emotion-focused coping strategy of Humor, a dysfunctional coping strategy of Venting to mitigate the influence of difficult situations. The research assumed the existence of positive differences between the assessment of determinants of burnout syndrome in terms of gender. The results reported a higher tendency of female entrepreneurs to be more often emotionally exhausted than males. Personal Accomplishment and Depersonalization did not report any statistically significant differences in terms of gender.
\end{abstract}

JEL Classification Numbers: A1, M1, L26, DOI: https://doi.org/10.12955/peb.v2.251

Keywords: Burnout syndrome. Coping strategies. Maslach Burnout Inventory, The Brief COPE, Entrepreneurs

\section{Introduction}

Each of us is unique and, therefore, the symptoms of burnout syndrome can slightly vary from person to person. The best way how to perceive burnout syndrome is to understand it as a mental state of exhaustion and as a result through the perception of certain characteristic that start to appear, e.g., low work efficiency, cynicism, loss of motivation, depersonalization, etc. (Smith, 2020). Carter (2013) says that burnout affects responsible, capable, and ambitious people who are used to putting the greatest effort into their work or passion, and it is considered as a gamble, especially for so-called high achievers, who do not realize or ignore that they work for a very long time, take on burdensome tasks and exert pressure on themselves. Burnout has become a serious problem nowadays and we can see that businessmen suffer from feelings of being alienated or angry, which can lead to workplace conflicts (Maroon, 2012). Work burnout is a type of overstraining that results from prolonged exposure to chronic and job-related stressors (Purvanova \& Muros, 2010). Nowadays, the widespread problem affects many professions but mostly medical students, early-career people like lawyers, nurses, teachers, artists, athletes, etc. (Galdino, Martins, Haddad, Robazzi, \& Birolim, 2016; Hamaideh, 2012). The syndrome is assessed by the Maslach Burnout Inventory and includes 3 subscales - Emotional Exhaustion (EE), which is a chronic state of emotional and physical depletion, caused by excessive and prolonged stress, Depersonalization (DP) or cynicism, can lead to alienation and apathy, low sense of Personal Accomplishment (PA) and may result in decreased productivity, decreased experience of success, and competence through work and low morale (Brubaker \& Beverly, 2019). Given the literature studied so far, we think that healthy relationships in a suitable environment, good work organization, the ability to use free time properly, and even learning to be assertive is very helpful. According to authors Brubaker \& Beverly (2019) education intelligence, age, and length of practice do not affect the state of burnout syndrome. Statements vary considerably when it comes to the length of work per job and some authors consider it as a high-risk factor (Pešek \& Praško, 2016). A Harvard medical school study reported that approximately ninety-six percent of senior executives feel burned out and the remaining four percent describe their condition as extreme burnout (Nisen, 2013). Three types of burnout exist, e.g., overload syndrome (frenetic) due to constant work demands or obligations, under-challenged syndrome (demotivating) causes feeling that nothing is developing in the right direction and total apathy comes, and finally there is worn-out syndrome (wear out) that causes frequent or a chronic need to avoid or

\footnotetext{
${ }^{1}$ Department of Managerial Psychology, The Faculty of Management, University of Prešov in Prešov, Slovak Republic, barbara.nicole.cigarska@smail.unipo.sk

${ }^{2}$ Department of Managerial Psychology, The Faculty of Management, University of Prešov in Prešov, Slovak Republic, zuzana.birknerova@unipo.sk
} 
ignore all duties (Jansen, 2016). According to Maslach et al. (1996) burnout syndrome is characterized by strong emotional exhaustion, depersonalization, or decreased professional achievement, and is common in occupations where individuals work every day with another people.

The next concept represents the ability to cope with extremely difficult and almost unmanageable situations or the ability to handle unusually difficult tasks. The Latin word colaphos, also known as a blow with the fist, represents the concept of dealing with difficult situations as a higher level of adaptation which we need to have to cope with extreme stress (World of Dictionary, 2021). According to the requirements of the situation, coping is changing for the same person over time. According to Hybenová (2010) it is considered as a disposition trait or addictive preference for approaching any problem, while others believe that it is a real effort with specific strategies which are applied in different types of situations. But the occurrence of anxiety negatively influences the way how entrepreneurs face stressors everyday which can be related to the usage of ineffective strategies (Govêia et al., 2018). Coping is an evolving process that changes in response to context, in an effort to manage internal or external demands. Successful coping involves the ability to adjust and change coping strategies in a way that facilitates positive results (Lazarus \& Folkman, 1987). Different classifications of coping strategies are mentioned in other studies. According to Roger et al. (1993) categorized coping strategies are adaptive, which include rational coping; and others are maladaptive strategies, which include emotional coping. Coping is defined as an effort of an individual to handle demands that are perceived as exceeding our forces (Monat \& Lazarus, 1991). According to Lazarus \& Folkman (1984), two major types of coping strategies exist in general, first are problem-focused coping strategies and second there is emotion-focused coping. Problem-focused coping is much more effective, it involves making a direct effort to change or modify stressors from the external environment, e.g., learning some new skills or finding alternative solutions. Emotion-focused coping is less effective because it involves the change of individual appraisals of the stressful situation with the aim to eliminate the necessity to take actions, e.g., wishful thinking or seeking any emotional support.

Gender affects almost every element in the process of stress as much as in the input, by determining whether the situation will be perceived as stressful, as in the output or in influencing coping responses and the health implications of stress reactions (Barnett et al., 1987). Social roles seem to be relevant in the stressful life experiences of women and men. It differs in the frequency of using of social roles and their experiences, e.g., women's position in the family and at work is less favorable because they carry a greater burden of demands and many limitations (Matud, 2004).

Markus, et al. (2018) add that differences in terms of gender are perceived in a wide range of disorders related to stress, e.g., women employees are more likely to become depressive and it leads to a higher rate of disability, sick-leaves and earlier retirements. According to authors (2018), men and women do not perceive stress differently, but both respond to stress physiologically differently, and dramatic transformations in gender roles, work-related burdens, have an impact on well-being and healthiness.

The aim of the research was to determine the existence of statistically significant differences between selected determinants of burnout syndrome (3) and coping strategies (14) in terms of gender among entrepreneurs. In our hypothesis, we assumed that there exist positive differences between the assessment of determinants of burnout syndrome (MBI methodology) in terms of gender and the assessment of coping strategies (Brief COPE Inventory) in terms of gender. The study aimed to assess the risks of burnout and describe which coping strategies male and female entrepreneurs used.

\section{Methodology}

The research was conducted through questionnaires such as the Maslach Burnout Inventory (MBI) methodology and The Brief COPE methodology (Maslach, Jackson \& Leiter, 1996; Carver, Scheier, \& Weintraub, 1989). A total number of entrepreneurs from the Slovak Republic $(\mathrm{N}=113)$ of which 68 were women $(60.2 \%)$ and 45 were men $(39.8 \%)$ in age from 19 to 60 years, with the average age of 36 years, participated in the research through an online questionary. Their answers were analyzed and evaluated in the program SPSS 22 by using a $t$-test for two independent selections. The first part of questionnaire focused on the intensity of feelings of entrepreneurs because burnout syndrome represents a complex psychological construct. The second part of questionnaire examined how entrepreneurs deal with stressful situations. Entrepreneurs had the opportunity to state what was the most powerful coping strategy in fighting with stress. 
The Maslach Burnout Inventory methodology consists of 22 questions, nine of which are focused on Emotional Exhaustion (EE), five questions examine Depersonalization (DP), and the last eight questions assess Personal Performance (PA) (Maslach, Jackson \& Leiter, 1996). Questions fall into three main aspects of the syndrome, which we also describe as selected determinants of burnout syndrome. Only one determinant is considered as positive, it is Personal Accomplishment, and the other two are considered as negative, they are Emotional Exhaustion and Depersonalization. Evaluation of the first part of the MBI questionnaire consists of adding up points of scoring subscales, while entrepreneurs have the opportunity to choose on a Likert scale from the following options, 0 - never, 1 - several times per year, 2 - monthly, 3 - several times per month, 4 - weekly, 5 - several times per week, 6 - daily. We perceive burnout syndrome as a continuum and that is why the MBI methodology determines the level of burnout in three stages, high, moderate, and low stage. High values of burnout are typical for determinants of emotional burnout and depersonalization, and low values that often indicate a possible state of burnout are typical for determinant of personal satisfaction.

The Brief COPE methodology is focused on the recognition of coping strategies with stressful situations that individuals choose at certain times. It was originally designed by Carver in 1997 from the original The Full COPE inventory, but due to its complexity was gradually reduced into a lower number of items (Carver, Scheier, \& Weintraub, 1989). In research, this methodology involves 28 items with a four-point scale of answers, 0 - I've not been doing this at all, 1 - I've been doing this sometimes, 2 I've been doing this often, 3 - I've been doing this a lot. The scale applies to the behavior of an entrepreneur in demanding situations. The items of the methodology are substantively divided into 14 subscales and every subscale is described by two questions, which deal with a certain strategy. The research was dedicated to identifying gender differences in the assessment of three selected determinants of burnout, which were Emotional Exhaustion, Depersonalization, and Personal Accomplishment. Attention was dedicated to assessing 14 coping strategies in terms of gender. Information obtained from entrepreneurs were verified in statistical program SPSS 22 by using a $t$-test for two independent selections by which was detected the existence of statistically significant differences in the assessment of the selected determinants of burnout (3) in terms of gender (Table 1) and the existence of statistically significant differences in the assessment of coping strategies (14) in terms of gender (Table 2).

The reliability was determined by assessing Cronbach's Alpha. The analysis revealed that the Maslach Burnout Inventory $(\alpha=0.883)$ and the Brief COPE Inventory $(\alpha=0.870)$ are reliable. The observed values of the Cronbach's Alpha coefficient indicated that the inner consistency of the items saturating specified components is within the range of acceptability.

\section{Results}

In terms of the analysis, a statistically significant differences was reported in the determinant of Emotional Exhaustion $t(111)=2.253, \mathrm{p}=0.043$, and the average score of women was higher $(\mathrm{M}=$ $2.840, \mathrm{SD}=0.827)$ in comparison to the average score of men $(\mathrm{M}=2.242, \mathrm{SD}=0.847)$ because they often used the possibility to answer - several times per month. According to the results, women had a tendency to be more often emotionally exhausted than men which could lead to anxiety and work-family conflicts. Determinants of Personal Accomplishment and Depersonalization reported no statistically significant differences in terms of gender (Table 1).

Table 1: Differences in the assessment of selected determinants of burnout in terms of gender

\begin{tabular}{|c|c|c|c|c|c|c|c|c|c|}
\hline $\begin{array}{c}\text { Determinants } \\
\text { of burnout syndrome }\end{array}$ & Gender & $\mathbf{N}$ & $\mathbf{M}$ & SD & $t$-test & df & Sig. & $\begin{array}{c}\text { Mean } \\
\text { difference }\end{array}$ & $\begin{array}{c}\text { SE } \\
\text { difference }\end{array}$ \\
\hline \multirow{2}{*}{$\begin{array}{c}\text { Emotional } \\
\text { Exhaustion } \\
\end{array}$} & women & 68 & 2.840 & 0.827 & \multirow{2}{*}{2.253} & \multirow{2}{*}{111} & \multirow{2}{*}{$0.043 *$} & \multirow{2}{*}{-0.201} & \multirow{2}{*}{0.161} \\
\hline & men & 45 & 2.242 & 0.847 & & & & & \\
\hline \multirow{2}{*}{ Depersonalization } & women & 68 & 2.200 & 0.840 & \multirow{2}{*}{1.420} & \multirow{2}{*}{111} & \multirow{2}{*}{0.159} & \multirow{2}{*}{-0.227} & \multirow{2}{*}{0.160} \\
\hline & men & 45 & 2.427 & 0.824 & & & & & \\
\hline \multirow{2}{*}{$\begin{array}{c}\text { Personal } \\
\text { Accomplishment }\end{array}$} & women & 68 & 2.694 & 0.743 & \multirow{2}{*}{0.107} & \multirow{2}{*}{111} & \multirow{2}{*}{1.915} & \multirow{2}{*}{0.01} & \multirow{2}{*}{137} \\
\hline & men & 45 & 2.680 & 0.666 & & & & & \\
\hline
\end{tabular}

A comparison of respondents in a representative sample of entrepreneurs showed statistically significant differences in terms of gender (Table 2) in the following four strategies. 
The strategy of active coping reported statistically significant differences $t(111)=2.036, \mathrm{p}=0.044$, and the average score of men $(\mathrm{M}=1.977, \mathrm{SD}=0.604)$ was significantly different in comparison to the average score of women $(\mathrm{M}=1.647, \mathrm{SD}=0.579)$. Men achieved a higher score in comparison to women since on the scale of answers they chose frequently the option - I've been doing this often. We assume that men put in effort to solve demanding situations actively and were not just sitting and waiting for help. Women approached the possibility to answer - I've been doing this sometimes.

The strategy of venting reported statistically significant differences $t(111)=2.269, \mathrm{p}=0.025$, and the average score of men $(\mathrm{M}=1.500, \mathrm{SD}=1.749)$ was significantly different in comparison to the average score of women $(\mathrm{M}=1.227, \mathrm{SD}=1.674)$. Men also achieved a higher score in comparison to women since their answers were split between the answers - I've been doing this sometimes, I've been doing this often. We assumed they were able to relax emotionally more, they were willing to share negative emotions, feelings and perceived it as an acceptable strategy to strengthen positive interpersonal relationships. Women achieved values very close to the answer - I've been doing this sometimes.

The strategy of planning reported statistically significant differences $t(111)=3.188, \mathrm{p}=0.002$, and the average score of men $(\mathrm{M}=2.233, \mathrm{SD}=0.634)$ was significantly different in comparison to the average score of women $(\mathrm{M}=1.750, \mathrm{SD}=0.619)$. Men took the initiative to plan and not to be surprised in the time of unexpected situations which was visible on the scale of their answers - I've been doing this often. We assumed that they enjoyed planning further steps which were supposed to handle demanding situations. Women mostly answered - I've been doing this sometimes.

The coping strategy of Humor reported statistically significant differences $t(80)=1.766, \mathrm{p}=0.081$, and the average score of women $(\mathrm{M}=1.125, \mathrm{SD}=0.660)$ was significantly different in comparison to the average score of men $(\mathrm{M}=0.866, \mathrm{SD}=0.821)$. This time the higher score was achieved by women since women approached often the possibility to answer - I've been doing this sometimes. We assumed that women searched for fun and enjoyed joking with others to escape negative thoughts. Men showed that they almost never made fun of demanding situations and they rather chose the possibility to relax.

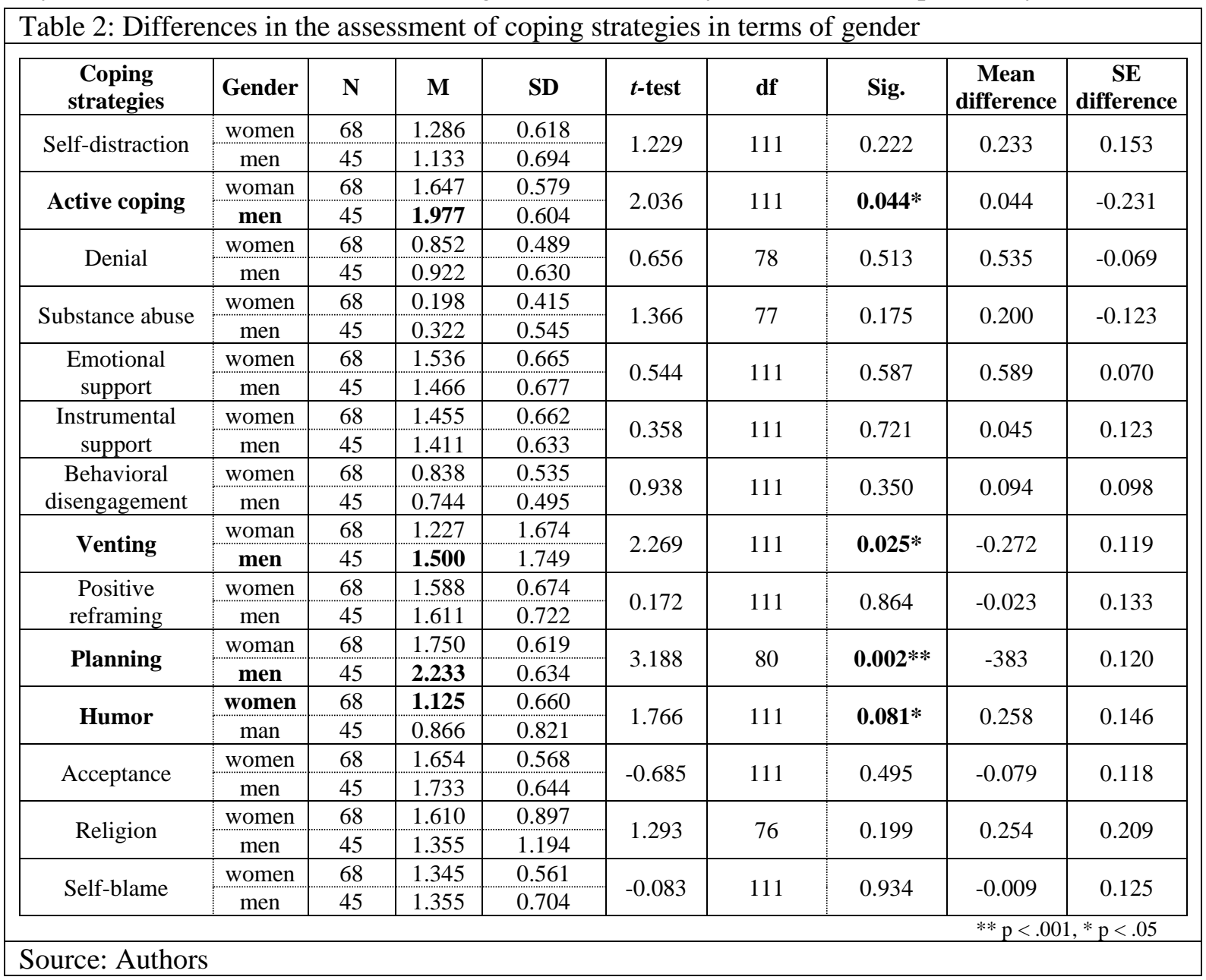




\section{Discussion}

The results of the independent-samples $t$-test reported statistically significant differences $(p<.05)$ in terms of gender in one determinant of burnout syndrome and four coping strategies. Research findings confirmed a difficulty of working in today's society, supersaturated by obligations. The interpreted results contributed to the significance and meaningfulness of the matter, considering the increasing state of cases of burnout syndrome worldwide.

In the determinant of Emotional Exhaustion, women achieved a higher score $(\mathrm{M}=2.840, \mathrm{SD}=0.827)$ in comparison to men $(\mathrm{M}=2.242, \mathrm{SD}=0.847)$, which shows their tendency to be more emotionally tired than men. We assume that female entrepreneurs manifested a greater loss of motivation, felt very tired and exhausted even after small tasks, showed a lack of strength to perform activities, often discussed life events in a more detailed way adding more emotions into them, resulting in long emotional fatigue.

In the strategy of Active coping, men achieved a higher average score $(M=1.977, S D=0.604)$ in comparison to the average score of women $(\mathrm{M}=1.647, \mathrm{SD}=0.579)$. In stressful situations, male entrepreneurs focused their efforts on the performance of some sort of activity that could mitigate the impact of stressors. Mostly it was doing some sport or having an active social life and active hobbies. We assume that these activities were closely related to planning or long thinking about problems and solutions. Entrepreneurs focused all their efforts on improving the conditions of their current situation, either by changing background or themselves.

In a strategy of Venting, men achieved a higher average score $(\mathrm{M}=1.500, \mathrm{SD}=1.749)$ in comparison to the average score of women $(\mathrm{M}=1.227, \mathrm{SD}=1.674)$. We assume that entrepreneurs had a tendency to share negative emotions which often included anger, blaming, and grumpiness in order to mitigate several effects of stress.

In the strategy of Planning, a higher average score was achieved by men $(M=2.233, S D=0.634)$ in comparison to women $(\mathrm{M}=1.750, \mathrm{SD}=0.619)$. Entrepreneurs focused their attention on fulfilling the tasks responsibly to achieve order and certainty in an unexpected stressful situation. We assume that they realized priorities, did not waste energy, had a good management and suitable strategies to delegate tasks. Eventually it was related to the determinant of Personal Accomplishment because when entrepreneurs managed to accomplish everything planned, they did not lose their motivation and desire to fight in difficult times.

Female entrepreneurs achieved a higher average score $(\mathrm{M}=1.125, \mathrm{SD}=0.660)$ in the strategy of Humor in comparison to the average score of men $(\mathrm{M}=0.866, \mathrm{SD}=0.821)$. Female entrepreneurs appreciated a cheerful society and as a strategy they sought entertainment as a temporary escape from stressors. We assume that they found this strategy as a modern way of so-called work enrichment since it could be a pleasant and, in many cases, effective way of cooperation in the workplace.

We believe that the study contributed to the matter of burnout and highlighted the seriousness of the extreme state of exhaustion since we assumed it often brings psychosomatic problems and declines in performances. Fortunately, the findings showed that entrepreneurs have different options to handle stress by helpful and effective coping strategies. The study emphasized burnout as a well-known phenomenon that is appropriate to focus on in occupations prone to burnout syndrome, e.g., entrepreneurs, students, managers, teachers, athletes, artists, etc.

A study by author Anderson (2000) was focused on social service workers with longer than two years' experience. The results reported that individuals perceived themselves that they use strategies of active coping (engaged) more often than strategies of avoidance coping to manage challenging situations (avoidant). Up to $62 \%$ of participants of the research achieved a higher score in the determinant of Emotional Exhaustion which researchers considered as the center of burnout syndrome. Entrepreneurs who used coping strategies of Active coping reported a much lower sense of Depersonalization, but on the other hand, they experienced a sense of personal satisfaction. People, using the strategy of solving a problem by avoidance, experienced a tendency to feel emotionally exhausted, depersonalized, and had a feeling of reduced Personal Accomplishment. In the end, the findings showed that neither strategies of active coping, nor strategies of avoidance saved the individuals from burnout syndrome. According to Jenaro et al. (2007) coping strategies do not completely prevent burnout syndrome but can help just as preventive solutions do. For example, work and salary satisfaction by using active coping strategies 
play an important role in increasing personal satisfaction. However, low working and salary satisfaction and also the ausage of passive or emotionally based coping strategies predict significantly increased Emotional Exhaustion.

Different studies reported that men had a tendency to use problem-focused strategies, e.g., behavioral manifestations, but women had a tendency to use emotion-focused strategies, e.g., typical emotional responses (Day \& Livingstone, 2003). Another study reported different information, that women were more problem-focused and active than men (Ben-Zur, \& Zeidner, 1996). According to Denton, Prus, \& Walters (2004) females felt more stress when they were exposed to demands and obligations because of gender, marital and social roles. The study of Matud (2004) reported that women scored significantly higher than men in chronic stress and especially in daily minor stressors. The women scored much higher than men in emotional coping styles and avoidance coping styles and much lower in rational coping and coping of detachment. Emotional inhibition was much higher in men. Results of the study suggested that women reported higher stress than men and coping styles of women were more focused on emotions. Anbumalar (2017) added that women and men were stressed by different types of situations. Males listed work-related events and finances as the main sources of their stress, and women had the tendency to list family and health-related situations. For example, college students experienced stress, related to examination pressure, rejection, financial problems, depression and also feelings of low self-esteem.

A study (Markus et al., 2018) investigated differences in terms of gender with a focus on personality, characteristics, mood, sleepiness and cognitive measures in a group of 103 clinically diagnosed burnout patients, who were involved in a rehabilitation program during five weeks in specialized centers in Austria. Results of the study revealed that women and men did not have any difference in depression scores, but a higher level was visible in women in the level of Emotional Exhaustion, reduced vitality, and vigilance. Moreover, they showed a higher level of tiredness and sleepiness which affected the cognitive performance of demanding executive control tasks. Also, gender differences were found in personality characteristics and coping strategies related to work in all determinants of burnout. Individuals who went through burnout still have a chance to live a happier and fulfilled life (Páleníková, 2019). We agree with the author and believe that the first step to a happy life is the realization of one's own value. In this context, we consider the research by Markiewicz (2019) focused on emotional intelligence (EQ) and coping to be interesting. The analysis between EQ and stress management strategies reported that a high degree of emotional intelligence supported the development of the strategy of solving a problem by avoidance. A tendency to focus on emotions during stressful situations was reduced. The research indicated a significant role of EQ, as a higher level of this form of intelligence corresponded to lower feelings of burnout. The author added that prevention plays an important role e.g., in adapting to the working environment.

\section{Limitations}

The sample of entrepreneurs is considered as a limitation of the research, therefore in the future, the authors are planning to broaden the research by including new respondents from different backgrounds. The plan is to enrich the matter with a new analysis of personality traits that affect stress levels or expose people to a potential risk of burnout. The authors are planning, by further analysis, to acquire new knowledge about the assessment of determinants of burnout syndrome and coping strategies in terms of gender among managers. The results and research are considered beneficial since they point to the expansion of burnout syndrome around the world. The research contributed to raising the awareness of stress, which can result in serious mental and physical health problems.

\section{Conclusion}

Some preferences and tendencies which we have and to which we are accustomed to contribute to how we react to stressful situations and expose us to an increased risk of burnout, e.g., perfectionism, emotional stability, pessimism, lack of self-belief, etc. We had the opportunity to find out that differences in terms of gender in reactions to stressors simply exist. The most enthusiastic individuals fall more often into difficult forms of burnout. We believe that the resulting severity of one's mental and physical condition stands as an indicator of one's original enthusiasm. On the one hand, it represents a difficult experience, but on the other hand, it can be the first step in knowing one's own identity and hence be the first step in developing a new personality and increase personal growth. According to our conclusions we consider prevention as the most powerful technique in enabling productive work and 
maintaining well-being. Based on the results and discussion, we conclude that entrepreneurs should support the necessity of increasing directed prevention and make time for relaxation, sports and other activities that help one to feel happy, not frustrated. Although the issue of burnout is predominantly in medical workers, we tried to point out another fields of occupation that are burdensome on workers.

\section{Acknowledgment}

This article was supported and financed by the scientific grant projects: GaPU 30/2020 - Grant Agency for Doctoral Students and Young Researchers of the University of Prešov in Prešov, KEGA 012PU4/2020: Trading Behavior - Creation of the subject and textbook for noneconomic study programs.

\section{References}

Anbumalar C., Dorathy Agines P., Jaswanti V.P., Priya D., Reniangelin D. (2017). Gender differences in perceived stress levels and coping strategies among college students. International Journal of Indian Psychology, 4(4). doi: $10.25215 / 0404.103$

Anderson, D. G. (2000). Coping strategies and burnout among veteran child protection workers. Child Abuse \& Neglect, 24(6), 839-848. doi:10.1016/s0145-2134(00)00143-5

Barnett, R. C., Biener, L., \& Baruch, G. K. (Eds.). (1987). Gender and Stress. New York, NY: Free Press.

Ben-Zur, H., \& Zeidner, M. (1996). Gender differences in coping reactions under community crisis and daily routine conditions. Personality and Individual Differences, 20(3), 331-340. doi:10.1016/0191-8869(95)00173-5

Brubaker, J. R., \& Beverly, E. A. (2020). Burnout, perceived stress, sleep quality, and smartphone use: A survey of osteopathic medical students. The Journal of the American Osteopathic Association, 120(1), 6-17. doi:10.7556/jaoa.2020.004

Carter, S. B. (2013, November 26). The tell tale signs of burnout ... Do you have them? Psychology Today. Retrieved from http://www.psychologytoday.com/blog/high-octane-women/201311/the-tell-tale-signs-burnout-do-you-have-them

Carver, C. S., Scheier, M. F., \& Weintraub, J. K. (1989). Assessing coping strategies: A theoretically based approach. Journal of Personality and Social Psychology, 56(2), 267-283. https://doi.org/10.1037/0022-3514.56.2.267

Day, A. L., \& Livingstone, H. A. (2003). Gender differences in perceptions of stressors and utilization of social support among university students. Canadian Journal of Behavioural Science. Revue Canadienne Des Sciences Du Comportement, 35(2), 73-83. doi:10.1037/h0087190

Denton, M., Prus, S., \& Walters, V. (2004). Gender differences in health: a Canadian study of the psychosocial, structural and behavioural determinants of health. Social Science \& Medicine (1982), 58(12), 2585-2600.

doi:10.1016/j.socscimed.2003.09.008

Galdino, M. J. Q., Martins, J. T., Haddad, M. do C. F. L., Robazzi, M. L. do C. C., \& Birolim, M. M. (2016). Síndrome de Burnout entre mestrandos e doutorandos em enfermagem [Burnout syndrome among master's and doctoral students in nursing]. Acta Paulista de Enfermagem, 29(1), 100-106. https://doi.org/10.1590/1982-0194201600014

Govêia, C. S., da Cruz, T. T. M., Miranda, D. B., Guimaraes, G. M. N., Ladeira, L., Tolentino, F. D. S., ... Magalhães., E. (2018). Association between burnout syndrome and anxiety in residents and anesthesiologists of the Federal District Brazilian Journal of Anesthesiology, 68(5), 442-446. ISSN 1806-907X. doi:10.1016/j.bjane.2018.02.006

Hamaideh, S. H. (2012). Gender differences in stressors and reactions to stressors among Jordanian university students. The International Journal of Social Psychiatry, 58(1), 26-33. doi:10.1177/0020764010382692

Hybenová, V. (2004). Zvládanie zátažových situácií a relaxačné techniky v práci výchovného poradcu [Coping with stressful situations and relaxation techniques in the work of an educational counselor]. Prešov: Krajská pedagogicko-psychologická poradňa

Jansen, J. (2016). Nevím, co chci, ale rozhodně ne tohle [I do not know what I want, but definitely not this]. Northwood, England: Management Press (International).

Jenaro, C., Flores, N., \& Arias, B. (2007). Burnout and coping in human service practitioners. Professional Psychology, Research and Practice, 38(1), 80-87. doi:10.1037/0735-7028.38.1.80

Lazarus, R. S., \& Folkman, S. (1984). Stress, Appraisal, and Coping. New York, NY: Springer Publishing.

Lazarus, R. S., \& Folkman, S. (1987). Transactional theory and research on emotions and coping. European Journal of Personality, 1(3), 141-169. doi:10.1002/per.2410010304

Markiewicz, K. (2019). Burnout as a Mediator of the Interrelations Between Emotional Intelligence and Stress Coping Strategies in Nurses. Acta Neuropsychologica, 17(3), 233-244. Retrieved from https://actaneuropsychologica.com/api/files/view/984500.pdf

Markus, C., Daniela, B., Paul, J., Markus, B., Andreas, F., Kathrin, B., ... Ilona, P. (2018). Gender differences in different dimensions of common burnout symptoms in a group of clinical burnout patients. Neuropsychiatry, 8(6), 1967-1976. doi:10.4172/Neuropsychiatry.1000539

Maroon, I. (2012). Syndrom vyhoření u sociálních pracovníku [Burnout syndrome in social workers]. Praha: Portál s.r.o. ISBN 978-80-262-0180-9.

Maslach, C., Jackson, S. E., \& Leiter, M. P. (1996). Maslach Burnout Inventory Manual (3rd ed.) (Vol. 3). Palo Alto, CA: Consulting Psychologists Press. 
Matud, M. P. (2004). Gender differences in stress and coping styles. Personality and Individual Differences, 37(7), 14011415. doi:10.1016/j.paid.2004.01.010

Monat, A. \& Lazarus, R. S. (1991). Stress and coping: An anthology (3rd ed.). New York, NY: Columbia University Press. Nisen, M. (2013, May 8). Why executive burnout is A such huge problem. Business Insider. Retrieved from https://www.businessinsider.com/ceo-burnout-is-a-growing-problem-2013-5

Páleníková, V. (2021). Psychické vyčerpanie a práca učitel’a [Mental exhaustion and teacher's work]. Retrieved February 6, 2021, from Komposyt.sk website: https://www.komposyt.sk/pre-odbornikov/psychologicka-cinnost/previewfile/v_palenikova_psychicke_vycerpanie_a_praca_ucitela-1494.pdf

Pešek, R., \& Praško, J. (2016). Syndrom vyhoření - Jak se prací a pomáháním druhým nezničit [Burnout syndrome - How not to be destroyed by work and helping others]. Pasparta. ISBN 978-80-88163-00-8.

Purvanova, R. K., \& Muros, J. P. (2010). Gender differences in burnout: A meta-analysis. Journal of Vocational Behavior, 77(2), 168-185. doi:10.1016/j.jvb.2010.04.006

Roger, D., Jarvis, G., \& Najarian, B. (1993). Detachment and coping: The construction and validation of a new scale for measuring coping strategies. Personality and Individual Differences, 15(6), 619-626. doi:10.1016/0191-8869(93)90003-1

Smith, M. (2020). Burnout prevention and treatment. HelpGuide.Org. Retrieved April 29, 2021, from https://www.helpguide.org/articles/stress/burnout-prevention-and-recovery.htm

World of Dictionary. (2021). Latin-English Dictionary. Colaphus. Retrieved April 29, 2021, from

https://worldofdictionary.com/dict/latin-english/meaning/colaphus 